\title{
Discrecionalidad y motivación del acto administrativo en la ley española de procedimiento administrativo
}

\author{
Discretionality and motivation of administrative act on \\ Administrative Procedure in Spanish Law
}

\author{
JAIME RODRÍGUEZ-ARANA MUÑOZ*
}

\begin{abstract}
Resumen: El artículo nos presenta una aproximación doctrinal al concepto de discrecionalidad y nos describe sus presupuestos técnicos. Seguidamente, el artículo hace hincapié en que resulta necesario que se incorpore, en todos los actos administrativos, alguna referencia racional que permita colegir con facilidad los argumentos lógicos de los que trae causa dicha resolución administrativa. Se constituye así, en la otra cara de la moneda, la motivación de la discrecionalidad, pues de lo contrario estaríamos entrando en el mundo de la arbitrariedad.
\end{abstract}

Palabras clave: Discrecionalidad - procedimiento administrativo - conceptos jurídicos indeterminados - administraciones públicas

Summary: This article offers a doctrinal approach to discretionality as a concept, and describes its technical assumptions. Then, emphasizes the need to incorporate in all the administrative actions some rational reference allowing to easily deduce logical arguments which derive from the administrative resolution. Thus, motivation represents the other side of the coin of discretionality; otherwise, we would be in an arbitrary world.

Key words: Discretionality - administrative procedure - undetermined legal concepts - public administrations

CONTENIDO: I. APROXIMACIÓN CONCEPTUAL. - II. ESQUEMA JURÍDICOFORMAL DE LOS PRESUPUESTOS TÉCNICOS DE LA DISCRECIONALIDAD: LÍNEAS EVOLUTIVAS. - II.1. LOS CONCEPTOS JURÍDICOS INDETERMINADOS: NOTAS GENÉRICAS. - II.2. LOS CONCEPTOS JURÍDICOS INDETERMINADOS: ELEMENTOS DE INTERPRETACIÓN. - II.3. DISCRECIONALIDAD: DESCUBRIMIENTO DEL ELEMENTO DE UNIÓN DE LA NORMA PARA LA APLICACIÓN O INAPLICACIÓN DE ACTOS DISCRECIONALES. - II.4. ANÁLISIS DE LOS COMPONENTES VALORATIVOS PARA LA FORMACIÓN Y EJECUCIÓN DEL ACTO DISCRECIONAL: PRESUPUESTOS TÉCNICOS PARA SU APLICACIÓN E INAPLICACIÓN. - III. MOTIVACIÓN Y DISCRECIONALIDAD EN EL ARTÍCULO 54 DE LA LEY DE RÉGIMEN JURÍDICO DE LAS ADMINISTRACIONES PÚBLICAS Y DEL PROCEDIMIENTO ADMINISTRATIVO COMÚN. - IV. REFLEXIÓN FINAL.

* Catedrático de Derecho Administrativo y Director del Departamento de Derecho Público de la Universidad de la Coruña Presidente del Foro Iberoamericano de Derecho Administrativo. El autor agradece al abogado Javier Sanmiguel su colaboración para la elaboración de este trabajo. 


\section{APROXIMACIÓN CONCEPTUAL}

Como es sabido, García-Trevijano define la discrecionalidad como una unidad de medida prefabricada por la propia administración — actuante o no, en el caso en cuestión - para actualizar y aplicar los conceptos estándares que se encierran en las normas. En este sentido, este autor entiende que el concepto clave para acceder a la naturaleza y articulación jurídicas de los actos discrecionales es el «interés público», cuyo substrato de análisis es preciso investigar en el contenido y objeto del acto administrativo de «actualización-aplicación» de la discrecionalidad. Es interesante, pues, dejar constancia — aunque solo sea de pasadade la incidencia del «interés público» como concepto central de una institución típica del Derecho administrativo. Se trata del concepto central — probablemente más acertadamente bajo la fórmula de interés general-, el cual es más amplio que el de interés público.

Villar Palasi, por su parte, señala que el meollo de la discrecionalidad se encuentra en la «actividad autónoma» de la administración, la cual viene marcada por el modo de determinación y el ejercicio de una actuación discrecional. En concreto, para Villar Palasi, «la discrecionalidad no supone una actuación según lo que subjetivamente estime apropiado y justo la Administración —que sí ocurre en Derecho Privado con el principio de libre autonomía de la voluntad—, sino la integración de la norma impresa, según los valores inminentes y los objetivos del ordenamiento». En esta línea de argumentación, el profesor Villar distingue cuatro ajustes en el binomio de adecuación «potestad discrecional y principio de legalidad», los cuales explicitan la determinación o indeterminación de las condiciones del ejercicio de la discrecionalidad:

- ajuste a la ley (no pueden contradecir a la ley)

- ajuste a la finalidad de la potestad

- ajuste a los criterios explícitos o implícitos de la ley

- ajuste a los principios generales

Para García Oviedo y Martínez Useros, obrar discrecionalmente equivale a obrar libremente, con la salvedad de acomodar la conducta a un fin público específico, de forma que la diferencia entre el acto discrecional y el acto arbitrario se percibe claramente: es una diferencia teleológica. Esta aproximación, cuyas raíces se entierran en las conocidas tesis del consejo de estado francés, se refiere al fin de la potestad discrecional, elemento que, en definitiva, asegura el ajuste de la actualidad administrativa a la realidad. Por eso, García Oviedo y Martínez Useros señalaron en su día que la virtualidad del acto discrecional consiste en el cumplimiento de una función acomodadora de la relación causal entre las decisiones del poder y los fines institucionales del mismo, dado que el valor 
de generalidad de los mandatos de las normas no se establecieron por ella las directrices de concreción de dicha realidad causal. En parecidos términos - siguen diciendo los autores citados-, allí donde el Derecho recae sobre elementos constantes en lo esencial, pueden construirse sistemas técnico-jurídicos que señalen límites estrechos a una apelación directa a los valores. Este es el caso del Derecho civil, en el que, como las relaciones y situaciones son, en lo fundamental, permanentes, es posible estructurarlo en instituciones en que puede ser operante el estricto instrumento lógico. La norma jurídica determina que dado un hecho concreto debe producirse una determinada consecuencia. En cambio, en términos generales, al Derecho administrativo le es fundamentalmente extraña semejante conformación técnico-jurídica. Esta ausencia explica la amplitud y frecuencia de la potestad discrecional.

Mozo Seoane, uno de los mejores especialistas del tema, señala que la discrecionalidad es una cualidad de los actos administrativos de simple valor relativo que se contrae a la apreciación de la idoneidad del resultado de un acto, $y$, por consiguiente, a la determinación de su objeto o contenido que no afecta ni a la competencia del órgano productor ni al fin de su generación. Por eso, se dice que no hay actos discrecionales puros, y que todo acto discrecional lo es solo en parte, ya que, en otra parte, es reglado (competencia y fin), o puede serlo o no, mas sin necesaria correlación en ambas indeterminaciones (oportunidad y forma). Con esto, volvemos a encontrar los inevitables momentos de la discrecionalidad.

\section{II.ESQUEMA JURÍDICO-FORMAL DE LOS PRESUPUESTOS TÉCNICOS DE LA DISCRECIONALIDAD: LÍNEAS EVOLUTIVAS}

\section{II.1. Los conceptos jurídicos indeterminados: notas genéricas}

La incorporación de la doctrina de los conceptos jurídicos indeterminados se importó y trajo de Alemania al acervo jurídico español, como nos ha enseñado el profesor García de Enterría. Ciertos sectores doctrinales prefieren, sin embargo, la expresión "concepto normativo indeterminado», de más precisión y exactitud, pues trata de conceptos que, procedentes de cualquier campo del conocimiento, se incorporan a una norma y adquieren una función y un sentido propios de esta.

Esta doctrina se une inseparablemente al tema de la discrecionalidad administrativa, aunque en la actualidad es necesario diferenciar como distintos los elementos valorativos - dentro del campo de lo volitivo, lo que la jurisprudencia española enmarca como discrecionalidad de juicio-. Estos últimos son los que se unen de una manera intensa a la teoría de los conceptos normativos indeterminados. 
En opinión de Mozo Seoane, no debe ocultarse que la cuestión de los conceptos indeterminados y su utilización por el lenguaje legal tiene, cuando menos, dos serios peligros. Por una parte, su empleo abusivo introduce un elemento adicional a la tarea —ya de por sí difícil— de interpretación y aplicación del Derecho, especialmente la tarea judicial. Y, por otra, en el ámbito de la ejecución administrativa de la ley, late siempre la amenaza de que se utilicen como fuente legitimadora de la arbitrariedad. Precisamente, para evitarlo se construyó la teoría de los conceptos normativos indeterminados.

Para Mozo Seoane, en el sector del ordenamiento administrativo abundan las proposiciones normativas cuyo supuesto de hecho aparece formulado con elementos imprecisos. Expresiones como interés público $-\mathrm{y}$ sus múltiples variantes-, urgencia, edificio ruinoso, justo precio, idoneidad, probidad, competencia profesional, necesidades del servicio, orden público (riesgo de alteraciones o peligro de perturbación), conveniencias de la economía nacional y tantas otras son moneda corriente.

Para García de Enterría, lo peculiar del concepto jurídico (normativo) indeterminado es la unidad de solución justa frente a lo característico de las potestades discrecionales: la pluralidad de soluciones justas posibles como consecuencia de su ejercicio. Así, la calificación en una circunstancia concreta no puede ser más que una: o hay utilidad pública o no la hay; o se da, en efecto, una perturbación del orden público o no se da; o el precio que se señala es justo, o no lo es. En cambio, la discrecionalidad consiste esencialmente en una cierta libertad de elección, según García de Enterría.

\section{II.2. Los conceptos jurídicos indeterminados: elementos de interpretación}

En este punto se produce una evolución de la doctrina de los conceptos normativos (jurídicos) indeterminados. El punto de inflexión gira en torno a la diferencia de estructura interna de dos procesos: el concepto normativo indeterminado pertenece al orden de lo cognoscitivo o intelectivo (juicio), en tanto que la discrecionalidad se mueve en el terreno de lo volitivo (elección). En este sentido, García de Enterría y Fernández Rodríguez señalan que la discrecionalidad es esencialmente una libertad de elección entre alternativas igualmente justas, o, si se prefiere, entre indiferentes jurídicos, porque la decisión se fundamenta en criterios extrajurídicos - de oportunidad, económicos, etcétera- no incluidos en la ley y remitidos al juicio subjetivo de la administración. Ahora bien, ipueden existir dos soluciones justas? ino será la capacidad de seleccionar la solución justa — de las legalmente posibles—que mejor se adecúa al interés público? 
Villar Palasi, siguiendo esta misma dirección, dice que, a priori, se caracteriza como una valoración querida y dependiente de la ley que aboca, por ello, una cuestión de teoría general de interpretación legal. Por tanto, el proceso de integración de un concepto jurídico indeterminado el precisar si se da o no- no puede ser un proceso volitivo de discrecionalidad, sino un proceso de juicio o estimación, de comprobación. Solo la estructura externa del concepto jurídico indeterminado es similar a la discrecionalidad en tanto ambos suponen una conducta optativa de la administración.

García-Trevijano, en la misma dirección, se pregunta si «iquiere decirse que cuando existan conceptos indeterminados tendremos discrecionalidad?». No exactamente. La discrecionalidad se purifica a través de su separación de otro concepto: la interpretación. Para García-Trevijano no puede haber discrecionalidad más que cuando se puede valorar, no cuando hay simple comprobación. Y en esta dicotomía entre «estructura interpretativa-comprobación empírica» radica la naturaleza conflictiva de la evolución del concepto de la discrecionalidad y sus soluciones de aplicación e inaplicación; en definitiva, su control ante la jurisdicción. Precisamente, en este contexto parece que se encuentran los nuevos enfoques de la legalidad de las múltiples soluciones que puede comportar una actuación discrecional: el análisis de los componentes valorativos del acto discrecional.

El profesor Nieto, siguiendo la tesis mayoritariamente aceptada, señala que, mediante la técnica de los conceptos jurídicos indeterminados, se ha conseguido diferenciar dentro de la masa equívoca de la interpretación de los hechos dos grupos de contornos muy claros para respetar solamente aquellas como propias de la discrecionalidad —una vez supuesta, claro está, la autorización legal—: voliciones y juicios.

En este sentido, García de Enterría dice que los efectos de esta construcción teórica respecto a la reducción y control de la discrecionalidad resultan, así, evidentemente decisivos: la integración de un concepto normativo indeterminado es, sencillamente, un proceso reglado como cualquier otro de aplicación e interpretación legal, plenamente controlable - y sustituible - en sede de fiscalización judicial, en virtud del principio de «unidad de solución justa» buscado por la norma que incorpora el concepto impreciso.

Este itinerario del camino de lo discrecional se bifurca y cobra nueva dimensión, contrapunto de la tesis anterior de la «unidad de solución justa». Para Sainz Moreno, una decisión discrecional implica «pluralidad de soluciones» legalmente permitidas, lo que convierte en justa cualquiera de las opciones que la administración ejercite. En realidad, la solución que adopte la administración en el marco de un poder discrecional es la que mejor se integra en el interés general desde la legalidad. 
Y ojalá que desde una perspectiva de la justicia, porque la administración está sometida a la ley, pero también a la razón. En consecuencia, sigue diciendo Sainz Moreno, estamos ante una diferencia sustancial, cualitativa, entre las dos formas de atribución legal de potestades: la potestad reglada y la potestad discrecional. Este nuevo sentido también lo encontramos cuando el autor afirma que los conceptos normativos indeterminados, aun cuando presentan un contenido que ha de ser precisado ante las circunstancias del caso concreto, también en abstracto son susceptibles de una definición objetiva - aunque ello resulte una operación más o menos difícil—. Teóricamente, la objetivación de su contenido es tan posible como la de un concepto normativo indeterminado, pues también el mandato contenido en este es, con frecuencia, solo relativo y necesitado de interpretación, de adecuación a la situación de hecho: la diferencia entre un concepto normativo determinado y otro indeterminado es simplemente cuantitativa, de grado, lo que se traducirá en una mayor dificultad de apreciación, pero en ambos casos posible y preconfigurada en la norma respectiva. En cambio, nada de esto puede predicarse de los supuestos de atribución de discrecionalidad, en los cuales la ley otorga al órgano administrativo una libertad de actuación dentro de cuyos márgenes este puede decidir en favor de una de las varias soluciones posibles - todas admisibles-. En este «reducto de libertad» no hay contenido objetivo previo, por lo que discrecionalidad y concepto normativo indeterminado obedecen a una ratio esencialmente distinta: su diferencia no es de grado, sino cualitativa. En mi opinión, sin embargo, al estar sometida la administración a la ley y al Derecho, tal y como establece el artículo 103 de la Constitución, en el ejercicio de la discrecionalidad debe haber una vinculación además de a la legalidad y al interés general, a la justicia.

El profesor Parejo Alfonso, en su obra sobre las funciones administrativas y jurisdiccionales, se aproxima a la discrecionalidad a partir de los principios constitucionales que deben reglamentar las condiciones mínimas de su aplicabilidad práctica ante la carencia de instrumentaciones jurídicas perfectamente delimitadas o delimitables de la acción y de las actividades administrativas. Estos principios son los de la interdicción de la arbitrariedad, la motivación de las resoluciones, la imparcialidad y objetividad, así como también el de la igualdad. Este autor se apunta a la tesis de la pluralidad de soluciones legítimas en materia de resoluciones discrecionales. Sus argumentaciones jurídicas descansan sobre los cimientos del voluntarismo o discrecionalidad de actuación, fundamentos que parecen coincidir con la teoría mixta americana del fact and law, una especie de interrelación e integración del supuesto de hecho normativo -insisto- en su consecuencia jurídica natural, siempre en apreciación subjetiva de la administración. Así, los hechos determinantes de la decisión no son posibles de fiscalizar por parte de los tribunales 
de justicia, salvo vulneración clara de reglas jurídicas básicas. Por consiguiente, tales acciones, cuando conllevan decisiones de tinte discrecional, deben pasar el tamiz de determinadas medidas jurídicas correlativas: el deber de determinación exhaustiva de los hechos y su selección informativa, el deber de ponderación de los propios hechos-base, o el deber de ponderación de los posibles efectos jurídicos y su interconexión hacia una pluralidad de soluciones legítimas en consonancia con el punto de partida prioritario en toda actuación administrativa: la interdicción de la arbitrariedad.

\section{II.3. Discrecionalidad: descubrimiento del elemento de unión de la norma para la aplicación o inaplicación da los actos discrecionales}

La discrecionalidad administrativa como concepto jurídico autónomo necesita acudir a la estructura lógica de la norma jurídica en su dimensión de conjunto de elementos que conforman una proposición normativa integradora de un mandato jurídico. La descripción de esta estructura es explicada de forma magistral por Larenz, al decir que la regla imaginada válida de «modo general» —es decir, no para un supuesto concreto determinado - tiene la forma lingüística de una proposición declarativa. En una proposición declarativa simple podemos diferenciar tres elementos: el sujeto de la proposición, el predicado de la proposición y la unión entre ambos (cópula), es decir, la coordinación predicado-sujeto. El sentido de esta coordinación acostumbra ser el de constatar un hecho dado a una conexión de sentido: «así es esto». Al sujeto de la proposición corresponde en la proposición jurídica (completa) el supuesto de hecho; al predicado, la consecuencia jurídica; finalmente, la consecuencia jurídica determinada en la proposición jurídica se coordina al supuesto de hecho determinado.

El profesor Gallego Anabitarte indagó en el método utilizado por la doctrina alemana dominante para señalar, en relación con lo expresado anteriormente, que la discrecionalidad radica en el elemento de unión o cópula de la norma jurídica. Desde este elemento se averiguará la naturaleza de la facultad discrecional o no del órgano administrativo llamado a aplicar la decisión. En diferentes doctrinas encontramos expresiones como la pretensión de delimitar y conceptuar técnicamente el enlace hecho-consecuencia jurídica: sentido de una orden de validez, forma potestativa u optativa, problema aparente provocado por la teoría del imperativo, otorgamiento de ámbito de libertad para su destinatario, sentido de habilitación discrecional, entre otros son enunciados del elemento de unión o cópula ya indicado. Forsthoff, por su parte, concibe el «elemento cópula» como la manifestación típica y primaria de atribución de discrecionalidad. Por ello, la elección de la consecuencia jurídica

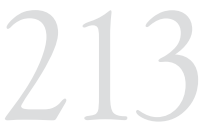

DISCRECIONALI-

DADY MOTIVACIÓN

DEL ACTO ADMI-

NISTRATIVO EN LA

LEY ESPAÑOLA DE

PROCEDIMIENTO

ADMINISTRATIVO

DISCRETIONALITY

AND MOTIVATION

OF ADMINIS-

TRATIVE ACT ON

ADMINISTRATIVE

PROCEDURE IN

SPANISH LAW 
entre los términos potestativos u optativos posibles es discrecional para la administración, pues todos gozan de igual validez jurídica.

Mozo Seoane propugna, en esta dirección, que tanto la atribución legal de la discrecionalidad como la medida exacta de la misma - esto es, los dos elementos del concepto: ámbito volitivo de la administración y límites de su ejercicio- constituyen un único problema de estricta interpretación jurídica. Concretamente, un fenómeno de la complejidad con que se manifiesta el poder discrecional solo puede ser aprehendido con un riguroso criterio de interpretación teleológica de la norma que descubra el sentido y la finalidad de las potestades administrativas, y, eventualmente, su contenido discrecional. Este mismo autor reconoce la abundancia de los fenómenos discrecionales y entiende que sus limitaciones aparecen en un doble sentido: no siempre la habilitación de la norma a un órgano administrativo determina un actuar libre del mismo, ya que sus condiciones vienen regladas y los ámbitos de la libertad administrativa comprenden otro tipo de análisis y de razonamiento jurídico.

\section{II.4. Análisis de los componentes valorativos para la for- mación y ejecución del acto discrecional: presu- puestos técnicos para su aplicación e inaplicación}

La moderna doctrina francesa trata de encontrar el concepto jurídico autónomo - la discrecionalidad — en la investigación de las directrices y de los objetivos de determinadas actuaciones sectoriales o generales de la «acción administrativa», la cual es dirigida, y pretendidamente coordinada, por el Poder Ejecutivo, así como su plasmación en la fotografía real, modulada por el principio de proporcionalidad. La jurisprudencia actual del Tribunal Supremo fija los senderos de la discrecionalidad en el mismo principio de proporcionalidad y en el principio de buena fe. Es famosa la sentencia sobre un caso de exportaciones-importaciones en materia de comercio exterior. El Tribunal Supremo obligó a rectificar una decisión discrecional de la administración por apartarse de su actuación precedente sin haber sido comunicado ni consultado tal cambio de parecer con los empresarios interesados en aras de la garantía de la buena fe.

Hoy, parece que entre los nuevos modos de enfoque de la legalidad multiforme de soluciones legales que comporta la discrecionalidad —desde un análisis de los componentes valorativos del actuar jurisdiccional— se encuentra la solución. Tales componentes deben venir presididos por la libertad, la justicia y la participación de los ciudadanos en las tareas político-administrativas, y su concreción natural se extendería en dos fases — siguiendo el concepto de Garcia-Trevijano- perfectamente diferenciadas: la fase de actualización y la fase de aplicación. La primera fase conlleva el análisis de dos momentos: el momento referido a los puntos 
de conexión de las materias que centran el fondo del asunto y el momento innovador o no del análisis de la realidad del tiempo en que se aplica la norma y su dinámica operativa. La segunda fase vendría determinada por el análisis del contenido inherente —o por la razón interna del actuar administrativo- - y por la adjetivación aplicativa de la materia-función objeto de la competencia que se desarrolla en el acto discrecional. Todo ello, es claro, implica un análisis exhaustivo de la relación que se produce entre el ámbito organizativo-administrativo y el ámbito personal del ciudadano: la dimensión del obrar hacia el ciudadano y su futuro. Como ejemplo, la materia de comercio se ha asociado, desde el punto de vista de las estructuras orgánicas administrativas, a otras varias de diferente naturaleza interna y externa por muy diversos imperativos - tanto en la administración central como en las administraciones autonómicas-: economía, trabajo, industria, turismo, consumo, etcétera. Su explicación puede adentrarnos todavía más en los terrenos a veces indescifrables de la discrecionalidad, y su descubrimiento en la construcción de realidades más favorables para todos los ciudadanos, así como en los tiempos que tocan vivir. De nuevo, pues, los derechos fundamentales y la sensibilidad del poder público hacia el hombre se convierten en piedras de toque de la actividad administrativa.

\section{III.MOTIVACIÓN Y DISCRECIONALIDAD EN EL ARTÍCULO 54 DE LA LEY DERÉGIMEN JURÍDICO DE LAS ADMINISTRACIONES PÚBLICAS Y DEL PROCEDIMIENTO ADMINISTRATIVO COMÚN}

En relación con la motivación, aunque solo sea exigible legalmente en los casos del artículo 54 de la Ley de Régimen Jurídico de las Administraciones Públicas y del Procedimiento Administrativo Común (LRJAPPAC) del 26 noviembre de 1992, no está de más que se incorpore en todos los actos administrativos alguna referencia racional que permita colegir con facilidad los argumentos lógicos de los que trae causa dicha resolución administrativa. La motivación es el correlato, la otra cara de la moneda de la discrecionalidad. Si la discrecionalidad no se motiva, entramos en el proceloso mundo de la arbitrariedad.

En un Estado de Derecho, la exigencia de objetividad que la propia Constitución española impone a la actuación de la administración debe plasmarse en todas sus manifestaciones de voluntad. Como los actos administrativos son la principal expresión de la voluntad administrativa, en ellos deberá aparecer de alguna manera el sello de la objetividad, cuya forma más sencilla es incorporar en su exteriorización los argumentos en los que se ha basado la administración para dictar el acto administrativo en cuestión. Como ha precisado el Tribunal Constitucional en su sentencia de 16 de junio de 1982, la motivación es necesaria para el 
debido conocimiento de los interesados y para la posible defensa de sus derechos, y debe darse con la amplitud necesaria para tal fin, pues solo expresando las razones que justifiquen la decisión es como el interesado puede después alegar cuanto le convenga para su defensa, sin subsumirse en la manifiesta indefensión que proscribe el artículo 24.1 de la Constitución - también extensivo a las resoluciones administrativas-. Más adelante, el propio Tribunal Constitucional, en sentencia 14/1991, dispuso que la motivación de los actos discrecionales garantiza que se ha actuado racional y no arbitrariamente, y permite un adecuado control de los actos discrecionales, además de exigir una motivación que, al menos, exprese apoyo en razones que faciliten conocer los criterios fundamentales de la decisión.

En efecto, aunque podría dedicarse un epígrafe especial, me parece que es pertinente analizar en este punto la motivación del acto administrativo. Esto porque, obviamente, es una cuestión relativa a los requisitos del acto administrativo y, sobre todo, porque es una cuestión central de la teoría del acto administrativo. La motivación, lo acabamos de señalar, es una manifestación — como pocas - de la objetividad a la que está condicionada la acción administrativa, precisamente, por el sentido racional del servicio al interés general que debe expresar toda manifestación de la actuación administrativa. Desde una perspectiva amplia, el artículo 103 de la Constitución, al mandar que la actividad administrativa refleje siempre el servicio objetivo al interés general, está obligando - insistoa que todos los actos administrativos sean un exponente de ese servicio objetivo al interés general. Y si así debe ser — como todos estamos de acuerdo-, entonces resulta que la motivación, así considerada, ha de ser una característica propia que distinga a los actos administrativos de otras categorías jurídicas.

En Alemania, como es sabido, la exigencia de la motivación no conoce excepciones. Ahora bien, en el Derecho español, si nos situamos en una aproximación más concreta, resulta que las exigencias de motivación, que han de ser generales para todos los actos administrativos, son imprescindibles en una serie de actos administrativos en los que - por razones de discrecionalidad o de restricción o limitación de las posiciones jurídicas de los particulares - la objetividad o racionalidad ha de ser expresada siempre y en todo caso. Además, junto a esta perspectiva, no puede olvidarse, como recuerda nuestro Tribunal Constitucional tempranamente, que en la propia motivación de los actos administrativos hay una razón de orden procesal: la defensa de los derechos e intereses legítimos del destinatario de un acto administrativo.

La motivación no es pura formalidad, no es fórmula de estilo ni cubrir el expediente. La motivación es, en mi opinión, una obra de artesanía jurídica que expresa el compromiso de una administración pública y de sus 
agentes por elaborar y confeccionar actos administrativos en el marco del Estado de Derecho. Con razón se ha dicho que la temperatura democrática de una administración pública se mide, entre otros factores, por el grado de calidad de la motivación de los actos administrativos. En efecto, cuando se cuida la motivación - cuando los funcionarios encargados de tal tarea han asumido la relevancia y trascendencia de su labor - se puede decir que nos encontramos ante una administración que intenta servir objetivamente el interés general. La objetividad, característica constitucional de la actuación administrativa, se satisface a partir de la racionalidad. Por eso, el Tribunal Supremo, en una sentencia del 10 de marzo de 2004 dice que la motivación, como ingrediente formal del acto administrativo, se cumple si del contenido del acto se deducen las razones determinantes de lo resuelto en el mismo.

Desde una perspectiva más general, la sentencia del Tribunal Supremo del 22 de febrero de 2005 señala que la motivación refuerza los principios de objetividad y transparencia de la actuación administrativa, y posibilita una plena tutela de los derechos e intereses legítimos de los ciudadanos. La motivación implica, pues, objetividad y efectividad de la tutela judicial. En el mismo sentido se pronunció el propio Tribunal Supremo a través de una sentencia del 29 de noviembre de 2006, al establecer que la motivación tiene por finalidad que el interesado conozca los motivos que conducen a la resolución con el fin, en su caso, de poder rebatirlos en la forma procedimental regulada al efecto. La motivación, pues, continua esta sentencia, es consecuencia de los principios de seguridad jurídica y de interdicción de la arbitrariedad enunciados en el apartado 3 del artículo 9 de la Constitución española y, también, desde otra perspectiva, puede considerarse como una exigencia constitucional impuesta no solo por el artículo 24.2 de la Constitución española, sino también por el artículo 103, en el que se trata del principio de legalidad en la actuación administrativa. Además, esta resolución judicial, con buen criterio, recuerda que la obligación de motivar es consecuencia también del derecho a una buena administración proclamado en el artículo 41 del Tratado de los Derechos Fundamentales de la Unión Europea cuando dispone que la obligación de la administración de motivar sus decisiones forma parte de tal derecho fundamental de la persona.

En efecto, la motivación es también una garantía de los derechos de los particulares, que así podrán conocer las razones que han impulsado a la administración pública a resolver en una determinada dirección y no en otra. La ausencia de motivación, cuando es preceptiva legalmente, puede entenderse como un vicio merecedor de nulidad de pleno derecho, pues provoca indefensión y se conculca así el derecho fundamental a la tutela judicial efectiva del artículo 24.1 de la Constitución, en aplicación del artículo 62.1, inciso a, de la LRJAPPAC. Sin embargo, en la mayoría de los casos, la falta de motivación es determinante de 
anulabilidad, sobre todo porque la jurisprudencia en la que la posibilidad de que la ausencia de motivación lesione un derecho fundamental no sigue ordinariamente este camino - probablemente - por razones históricas. Como ejemplo, tenemos a la doctrina de la sentencia del Tribunal Supremo de 13 de febrero de 1992. Sin embargo, la ausencia de motivación nos parece que puede lesionar gravemente - Constitución en mano- el derecho a la tutela judicial efectiva, al quedarse el particular sin los argumentos para impetrar la tutela judicial a que siempre tiene derecho.

Si se considera que la motivación no es más que un requisito formal de los actos administrativos en los que legalmente sea procedente, entonces su ausencia o deficiente formulación es merecedora de la sanción de la anulabilidad, de la nulidad relativa o, en todo caso, constitutiva de irregularidad no invalidante. El deslinde de ambos conceptos, como señala una sentencia del Tribunal Supremo de 1 de octubre de 1988, se ha de hacer indagando si realmente ha existido una ignorancia de los motivos que fundan la actuación administrativa y si, por tanto, se ha producido o no la indefensión del administrado. Ahora bien, si admitimos que estamos ante una cuestión material, de fondo, y se produce una lesión de derechos fundamentales con su omisión — tal y como señalaba antes-, entonces, como también admiten González Pérez y González Navarro, podríamos estar ante un supuesto de nulidad absoluta del artículo 62.1, inciso a, de la LRJAPPAC. Esta doctrina, sin embargo, cuenta con el no pequeño obstáculo de que la jurisprudencia del Tribunal Supremo sigue considerando, en general, que la motivación es un requisito formal, según la sentencia del 26 de noviembre de 1987. En sentido contrario, encontramos una progresiva sentencia del 20 de noviembre de 1998 que entiende, con toda lógica jurídica, que la omisión de la motivación «puede generar la indefensión prohibida por el artículo 24.1 de la Constitución». Para esta sentencia, la motivación no es un requisito formal, sino «que lo es de fondo [...] porque solo a través de los motivos pueden los interesados conocer las razones que justifican el acto, necesarios para que la jurisdicción contencioso administrativa pueda controlar la actividad de la Administración». El argumento fundamental para considerar que la motivación no es solo un requisito formal reside en que la principal nota que la Constitución atribuye a la administración es la del servicio objetivo al interés general. Y en esta tarea, la motivación de los actos es sencillamente esencial para tal servicio objetivo al interés general.

¿Ha de constar la motivación en el cuerpo del acto? ipuede encontrarse en el expediente administrativo? La jurisprudencia ha entendido que aunque lo normal es que la motivación se encuentre en la redacción material del acto es posible que sea fácilmente deducible del conjunto del expediente. Es más, puede que la motivación se encuentre en las memorias del expediente en cuestión, algo que quien conozca el funcio- 
namiento ordinario y real de la administración sabe que ocurre muchas veces. El propio Tribunal Supremo, en su sentencia del 21 de enero de 2003, entiende que la motivación «puede hacerse bien directamente bien por referencia a informes o dictámenes obrantes en el expediente». En el mismo sentido, la reciente sentencia del Tribunal Supremo del 24 de junio de 2008 recuerda que la motivación de los actos administrativos debe integrarse con los documentos obrantes en el expediente, de manera que la obligación de motivación de los actos discrecionales queda cumplida si con tal documentación los afectados conocen las razones que han llevado a la administración a adoptar una determinada resolución, y si ello les permite adoptar una adecuada defensa de sus intereses.

En estos casos, el particular habrá de tener acceso al expediente, porque si el interesado no tiene posibilidad de acceso estamos en un caso de indefensión material. En cualquier caso, lo mejor siempre es que la motivación se encuentre en el texto final del acto administrativo, pues, de esta manera, en el cuerpo del acto estaría todo lo relevante desde el punto de vista jurídico.

Si la motivación se hace directamente habrá de realizarse «con sucinta referencia de hechos y fundamentos de derecho», según dispone el primer parágrafo del artículo 54 de la LRJAPPAC. El Tribunal Supremo, por sentencia del 10 de marzo de 2003, entiende que «la motivación no significa un reconocimiento exhaustivo y detallado, pero tampoco una formula convencional ni meramente ritual, sino la especificación de la causa, esto es, la adecuación del acto al fin perseguido; por ello, para cumplir este requisito formal se precisa la fijación de los hechos determinantes, su subsunción en la norma y una especificación sucinta de las razones por las que este se deduce y resulte adecuada la resolución». Es decir, en la motivación, de manera sucinta, hay que desvelar las razones que en virtud de los hechos concretos han aconsejado al órgano administrativo a resolver en determinado sentido. La comunicación de la causa del acto, esa explicación de las razones en relación con los hechos, es la principal tarea que ha de ocupar al autor de la motivación que, insisto, debe ser una obra de artesanía, pues en la motivación de los actos nos jugamos valores — como señalamos anteriormente- esenciales del Estado de Derecho.

La expresión «sucinta referencia a los hechos y supuestos de derecho» — dice el Tribunal Supremo en una sentencia del 5 de mayo de 1999no permite a la administración reducir el alcance de la motivación a «una genérica remisión al contenido de preceptos legales, porque esa circunstancia no evita la indefensión del solicitante, el cual no puede llegar a conocer la razón cabal de la negativa, ni, consiguientemente, argumentar con eficacia la impugnación de esa denegación». Lo que es pertinente para cumplir con el sentido del parágrafo primero del



DISCRECIONALI-

DADY MOTIVACIÓN

DEL ACTO ADMI-

NISTRATIVO EN LA

LEY ESPAÑOLA DE

PROCEDIMIENTO

ADMINISTRATIVO

DISCRETIONALITY

AND MOTIVATION

OF ADMINIS-

TRATIVE ACT ON

ADMINISTRATIVE

PROCEDURE IN

SPANISH LAW 
artículo 54 de la LRJAPPAC es, como también ha señalado el Tribunal Supremo en su sentencia del 15 de febrero de 1991, «dar razón plena del proceso lógico y jurídico que determina la decisión». Y para ello no es menester una extensión amplia, sino la adecuada para cumplir con el fin de la motivación. En este sentido, como también ha tenido ocasión de señalar el Tribunal Supremo en sentencia del 12 de enero de 1998, «la suficiencia de la motivación viene determinada por un punto de referencia obligado, cual es la mayor o menor necesidad de un razonamiento más extenso o conciso, según las circunstancias que hayan de explicarse y las fundamentaciones que se precisen».

La motivación de los actos es, más que una cuestión de orden cuantitativo, una materia que debe resolverse desde la perspectiva cualitativa. La motivación, pues, no se acredita con una prolija y larga explicación necesariamente, sino con los argumentos apropiados al caso concreto, que en muchos casos podrán realizarse en breves líneas. Será la naturaleza de cada caso la que determine la extensión de la motivación. Como regla, la clave reside en explicitar convincentemente - y desde el punto de vista racional — las causas que han determinado que, por ejemplo, un poder discrecional se concrete en un sentido específico.

La motivación, como señala Bocanegra, consiste en una operación jurídica dirigida a que la administración autora del acto revele al interés público que lo justifica las razones de la adecuación del acto al fin de servicio objetivo. En los casos de poderes discrecionales, la motivación es fundamental, puesto que en estos supuestos se produce un juicio o una ponderación administrativa que lleva a la opción por una determinada solución de entre varias legalmente posibles, por lo que las exigencias generales de objetividad — que siempre acompañan a la actividad administrativa - son particularmente intensas.

Realmente, si la fuerza jurídica del acto administrativo procede de su presunción de legitimidad, de su adecuación al interés general, parece lógico que la motivación esté conectada no solo a las razones del caso concreto, sino también, de forma más general, a las razones de interés público que justifican la confección del acto administrativo.

Aunque -como veremos a continuación - la motivación es exigible legalmente en determinados casos, pienso que el legislador lo que hace es obligar en ciertos supuestos a una motivación específica, dada la naturaleza del acto de que se trate. Con carácter general, el artículo 103 de la Constitución, en cuanto dispone que la administración actúa al servicio objetivo del interés general, parece reclamar que todas las actuaciones de la administración sean objetivas, lo que necesariamente habrá de traducirse en actuaciones racionales, en actuaciones motivadas en argumentos de interés público concretos. 
Analicemos, a continuación, el precepto que el legislador dedica a la motivación, que es el 54 de la LRJAPPAC, y que se encuentra ubicado en el capítulo segundo del título quinto, bajo la rúbrica de requisitos del acto administrativo:

1. Serán motivados, con sucinta referencia de hechos y fundamentos de derecho:

(i) Los actos que limiten derechos subjetivos o intereses legítimos.

(ii) Los actos que resuelvan procedimientos de revisión de oficio de disposiciones o actos administrativos, recursos administrativos, reclamaciones previas a la vía judicial y procedimientos de arbitraje.

(iii) Los que se separen del criterio seguido en actuaciones precedentes o del dictamen de órganos consultivos.

(iv) Los acuerdos de suspensión de actos, cualesquiera que sea el motivo de esta, así como la adopción de medidas provisionales previstas en los artículos 72 y 136 de esta Ley.

(v) Los acuerdos de aplicación de la tramitación de urgencia o de ampliación de plazos.

(vi) Los que se dicten en el ejercicio de potestades discrecionales, así como los que deban serlo en virtud de disposición legal o reglamentaria expresa.

2. La motivación de los actos que pongan fin a los procedimientos selectivos y de concurrencia competitiva se realizará de conformidad con lo que dispongan las normas que regulen sus convocatorias, debiendo, en todo caso, quedar acreditados en el procedimiento los fundamentos de la resolución que se adopte.

La motivación, como ha señalado atinadamente el Tribunal Supremo, es una exigencia constitucional que trae causa del artículo 9, el cual sanciona el principio de sujeción de los poderes públicos a la Constitución y al resto del ordenamiento jurídico, así como prohíbe la arbitrariedad y reclama el servicio objetivo al interés general, a la vez que también se concentra en el sometimiento pleno de la administración a la ley y al derecho; y del artículo 23.2, el cual dispone el principio de acceso en condiciones de igualdad a la función administrativa. Así, la sentencia del 29 de septiembre de 1988 señala que:

[...] cuando se dice que la discrecionalidad no es arbitrariedad se está diciendo precisamente, entre otras cosas, que incluso las llamadas decisiones discrecionales - y ninguna decisión lo es de manera total — han de ser motivadas. Lo contrario chocaría con preceptos de rango constitucional como los siguientes: artículo 9.1 -sujeción de los poderes públicos a la Constitución y al resto del Ordenamiento jurídico;

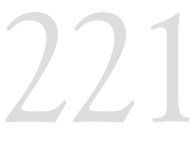

DISCRECIONALI-

DAD Y MOTIVACIÓN

DEL ACTO ADMI-

NISTRATIVO EN LA

LEY ESPAÑOLA DE

PROCEDIMIENTO

ADMINISTRATIVO

DISCRETIONALITY

AND MOTIVATION

OF ADMINIS-

TRATIVE ACT ON

ADMINISTRATIVE

PROCEDURE IN

SPANISH LAW 
artículo 9.3 -interdicción de la arbitrariedad-; artículo 103 -sujeción plena a la ley, y, además, al derecha que es previa a aquélla.

Efectivamente, si convenimos — como decía Locke-que la arbitrariedad es la ausencia de racionalidad, todos los actos del poder ejecutivo y de la administración han de ser racionales. Por ello, también desde esta perspectiva más abstracta, puede afirmarse que la exigencia de motivación es inherente a la propia esencia y razón de ser de la administración pública.

El marco constitucional de la motivación de los actos administrativos —que es claro y contundente- refleja hasta qué punto nos hallamos ante una obligación constitucional, conectada a su propia esencia y justificación institucional por parte de la administración. El citado artículo 103.1, al exigir la actuación de la administración pública al servicio objetivo del interés general, dispone claramente que la objetividad —esto es, la racionalidad - debe ser nota distintiva de la actuación administrativa, sea esta por acto o por contrato. La administración, sea cual sea su forma de expresión, siempre y en todo caso, ha de atender a la objetividad. De lo contrario, si nos situamos en esquemas de subjetividad y de arbitrariedad, estaríamos violando nada menos que uno de los principios fundacionales del Estado de Derecho. Desde otro punto de vista, la sentencia del Tribunal Supremo de 5 de diciembre de 1990 llega a la misma conclusión, al señalar que «las exigencias efectivas del Estado de Derecho ha determinado el alumbramiento de técnicas que permiten el control judicial de la Administración». Como los fines que la justifican son fines de interés público, y el interés público ha de gestionarse de forma objetiva, resulta que el Estado de Derecho reclama de la función administrativa una acción racional, objetiva y congruente con los fines de interés público que debe servir.

En parecidos términos se expresa la sentencia del Tribunal Supremo del 14 de septiembre de 1994 —así como la sentencia del 11 de diciembre de 1998-, cuando señala, en los artículos 9.1 y 103.1, que «el sometimiento de la actuación administrativa a la ley y al derecho, la interdicción de la arbitrariedad de los poderes públicos, y el control que corresponde a los tribunales de la legalidad de la legalidad de la actividad administrativa y de ese sometimiento a la ley demandan la motivación de los actos administrativos en garantía de la seguridad jurídica, de la igual aplicación de la ley y del derecho a la igual protección jurídica». Esta jurisprudencia, pues, parece inclinarse por la existencia de una exigencia constitucional general de motivación, la cual se desprende del contexto constitucional, y especialmente de los artículos 9, 103 y 106.

El alcance de la motivación, como dispone la sentencia anterior, «debe realizarse con la amplitud necesaria para su debido conocimiento y posterior defensa, con lo que la motivación del acto se conecta con el 
derecho fundamental a la tutela judicial efectiva y el derecho de defensa». Es decir, la motivación, en cuanto exteriorización de los argumentos racionales del acto, permite una mejor defensa del destinatario del acto, la cual está encaminada — -si es que el acto lesiona su posición jurídicaa recurrirlo sea en vía administrativa o en vía judicial. De esta manera, si es que se impide el ejercicio del derecho a la tutela judicial efectiva y el derecho a la defensa, se está lesionando un derecho fundamental de los que dan lugar, por mandato del artículo 62.1, inciso a, a la nulidad absoluta, la nulidad de pleno derecho. La perspectiva de la tutela judicial efectiva es tan importante debido a que afecta a un derecho fundamental de la persona. Sin embargo, la razón constitucional de la motivación reside en la exigencia de objetividad que ha de tener cualquier manifestación de voluntad de la administración. Lógicamente, si tal objetividad acompaña a las actuaciones administrativas, entonces será más fácil —de darse el caso— impugnar o recurrir dicho acto, puesto que las razones de su confección permiten la reacción jurídica en su contra.

La sentencia del 24 de marzo de 2000 del Tribunal Supremo ofrece una buena definición de motivación:

El Ordenamiento jurídico viene exigiendo la motivación con relación a ciertos actos haciendo consistir aquélla en la necesidad de hacer públicas las razones de hecho y de derecho que los justifican y fundamentan con las finalidades de permitir el control indirecto de la opinión pública, para que no aparezca el acto como manifestación voluntarista de un órgano sin otro apoyo que el ilegítimo de una simple decisión autoritaria e injustificada, de permitir el control jurisdiccional de dichos actos en los que la motivación es valiosísimo elemento para determinar si se ajusta o no a derecho, $\mathrm{y}$ de dar a conocer a sus destinatarios las razones en que aquéllos se asientan, único modo de que puedan decidir sobre la pertinencia de su impugnación y sobre los fundamentos de esta, al margen de constituir, la motivación, el ejercicio de una elegante cortesía siempre deseable.

En términos generales, toda la actuación administrativa, en la medida en que debe ser servicio objetivo al interés general, ha de ser razonada y mínimamente motivada. Ahora bien, aun siendo esto así en general, el legislador ha querido ofrecer un régimen especial de motivación para una serie de actos en los que la necesidad de exteriorizar la racionalidad es siempre necesaria, dada su conexión con la esfera jurídica del particular destinatario del acto administrativo. Tal régimen se encuentra, como sabemos, en el artículo 54 de la LRJAPPAC anteriormente transcrito.

De acuerdo con el artículo 54.1, la motivación consiste en una operación de comunicación de los argumentos de hecho y de derecho en que 
se funda un determinado acto administrativo. Es decir, como recuerda el Tribunal Supremo en su sentencia del 30 de noviembre de 1999, la motivación consiste en:

La necesidad de hacer públicas las razones de hecho y de derecho que los justifican y los fundamentan con las finalidades de permitir el control indirecto de la opinión pública, para que no aparezca el acto como manifestación voluntarista de un órgano sin otro apoyo que el ilegítimo de una simple decisión autoritaria e injustificada, de permitir el control jurisdiccional de dichos actos en los que la motivación es valiosísimo elemento para determinar si se ajusta o no a Derecho, y de dar a conocer a sus destinatarios las razones en que aquéllos se asientan, único modo de que puedan decidir sobre la pertinencia o impertinencia de de su impugnación y sobre los fundamentos de esta, al margen de constituir, la motivación, el ejercicio de una elegante cortesía siempre deseable.

La exteriorización de esas razones de hecho y de derecho ha de tener una adecuada armonía y congruencia, pues, de no haberla, de constituir un conjunto de argumentaciones inconexas y sin relación de causalidad, no se podrían colegir las razones reales de la producción del acto y, por lo tanto, no estaríamos en una motivación adecuada a los postulados de un Estado de Derecho.

Es verdad que el artículo 54 solo exige la motivación para una serie de actos. Sin embargo, como ya señalamos con anterioridad, la motivación general es exigible a todos los actos administrativos en el Estado de Derecho, sin perjuicio de que, en determinados casos, debido a su especial relevancia, trascendencia o relación con los ciudadanos, esta deba ser especialmente cuidadosa. En cualquier caso, la propia jurisprudencia, dados los términos tan amplios en que está redactado el artículo 54, no ha tenido empacho alguno en admitir que, efectivamente, la motivación es la regla general tal y como así ha manifestado la sentencia del Tribunal Supremo del 11 de diciembre de 2002.

En primer lugar, según el precepto que comentamos, han de ser motivados «los actos que limiten derechos subjetivos o intereses legítimos». La razón es obvia, puesto que estamos ante actos administrativos desfavorables para los ciudadanos. Como han señalado González Pérez y González Navarro, la motivación se exige, en este supuesto, a todo acto administrativo que suponga una limitación a la actividad del administrado que no estuviera prohibida o que estuviera condicionada a la adopción del acto. Se trata de motivación de actos — no de normas-, y de actos que limiten derechos subjetivos, no de actos delimitadores, tal y como ha entendido la sentencia del Tribunal Supremo del 8 de junio de 1999.

En segundo lugar, el artículo 54 se refiere a los «actos administrativos que resuelvan procedimientos de revisión de oficio, recursos administrativos, 
reclamaciones previas a la vía judicial y procedimientos de arbitraje». Es decir, se trata de actos que tienen especial trascendencia por estar llamados a resolver procedimientos de revisión de oficio, procedimientos en los que es la propia administración quien ha decido someter un acto perfecto a revisión por entender que podría incurrir en nulidad de pleno derecho o en anulabilidad. Igualmente, es ejercicio de poder discrecional la resolución de un recurso administrativo, como también lo son los actos que resuelven las reclamaciones previas. En todos estos casos, nos encontramos ante una función de naturaleza judicial de la administración y, por ello, parece razonable exigir la motivación a un acto administrativo que dirima controversias o resuelve conflictos jurídicos. En efecto, en estos casos, la forma de redactar el acto tiene un gran parecido con una sentencia. Los supuestos de hecho y los fundamentos de derecho conducen, a través de la razón y la lógica, a un determinado pronunciamiento, que, en caso de desestimación de la pretensión del recurrente, debe ser convenientemente argumentado.

En tercer lugar, nos encontramos con los actos que se separan del criterio seguido en actuaciones precedentes o del dictamen de órganos consultivos. La exigencia legal de motivación en estos casos no reclama demasiados comentarios, ya que, en los supuestos en los que la decisión administrativa se aparta del precedente o desconoce los informes de órganos consultivos, el esfuerzo de racionalidad debe ser mayor para explicar el sentido de dicho acto administrativo. El Tribunal Supremo ha dejado bien claro que en los casos de renovación de concesiones de dominio público, como señalan González Pérez y González Navarro, concurre tal obligación legal. Así, por ejemplo, la sentencia del 24 de febrero de 1999 dice que «los actos originarios impugnados debieron ser motivados, porque esa quiebra de anteriores renovaciones significaba dar al traste con el criterio seguido en actuaciones precedentes». La jurisprudencia —en su sentencia del 5 de octubre de 1988 — también ha exigido que se motiven los actos de trámite que integran el procedimiento y que se separan del mantenido en otros actos anteriores o de órganos consultivos, así como - según sentencia del Tribunal Supremo de 29 de septiembre de 1988 - en el caso del acto que se aparta de la propuesta de resolución. El valor jurídico del precedente administrativo es extraordinariamente importante porque la tarea administrativa es una tarea reiterada, conocida por los ciudadanos y, desde este punto de vista, previsible. En determinados casos, si concurren ciertas circunstancias, se actúa siempre en el mismo sentido. Si, repentinamente, en estos supuestos, se quiebra la confianza legítima - la buena fe de los ciudadanos en la racionalidad de la administración sin explicación-, entramos de lleno en el proceloso mundo de la arbitrariedad y la subjetividad, los cuales, como sabemos, se encuentran en la antípodas del Estado de Derecho. 
En cuarto lugar, la LRJAPPAC extiende la motivación a los acuerdos de suspensión, cualquiera que sea el motivo de esta. También es lógico que un acuerdo administrativo que resuelve un incidente de paralización provisional de los efectos de un acto administrativo sea objeto de una motivación esmerada. Efectivamente, en estos casos, se ventila nada menos que la suspensión de la ejecutividad de un acto administrativo, la detención provisional de los efectos de un acto que se presume ha sido dictado de acuerdo con la presunción de legitimidad y legalidad, ya que se tiene la presunción de que está inspirado en razones de interés general — de ahí su fuerza de obligar-. Y si la ejecutividad, como expresión de la autotutela administrativa, se funda sobre la presunción de congruencia con el interés general que acompaña a los actos administrativos — cuando estos van a ser retrasados en su ejecutividad — es lógico que tal decisión se motive suficientemente en razones de interés general.

En quinto lugar, también han de motivarse los actos de aplicación de la tramitación de urgencia o de ampliación de plazos. Es fácil colegir que el acto por el que se declara una expropiación forzosa urgente deba ser especialmente motivado. En el mismo sentido, cuando de ampliar un plazo se trata, igualmente hay que explicar el porqué del acto. En estos supuestos en los que la administración ejerce poderes especiales, la motivación es más relevante. Podría argumentarse que tales supuestos lo son, por su especial naturaleza, de discrecionalidad. Y como el precepto que analizamos exige la motivación en todas las manifestaciones de las potestades discrecionales administrativas, según la letra $\mathrm{f}$ del artículo 54.1 de la LRJAPPAC, se podría concluir que este supuesto, como otros del precepto, no hace falta por redundante. Es cierto, y siendo la mayor parte de los actos discrecionales, que se haga una mención a los más importantes no afecta al régimen general del artículo 54.1 de la LRJAPPAC. En estos supuestos, la motivación — dado que nos encontramos ante poderes discrecionales - habrá de venir fundada, como señalan González Pérez y González Navarro, en razones de interés público. Es lógico puesto que, por ejemplo, la declaración de emergencia de una contratación administrativa vendrá aconsejada por razones concretas, detalladas de interés público. Igualmente, la ampliación de un plazo en un determinado procedimiento habrá de atender a exigencias de interés general, pues, de lo contrario, pareciera que tal medida no tendría sentido.

En sexto lugar, el artículo 54.1 de la LRJAPPAC se refiere genéricamente a la motivación de todos los actos que se dicten en el ejercicio de poderes discrecionales. Si la motivación ha de ser la regla general de acuerdo con la exigencia constitucional de servicio objetivo al interés general cuando se trata de actos en los que la administración dispone de un ámbito de libre apreciación, tal obligación es mayor, así como de un alcance más concreto y específico. La motivación se expresa en el acto 
administrativo a través de la exteriorización de los criterios en los que basa su confección, de acuerdo con las exigencias — concretas y específicas- del interés general.

Pues bien, si resulta que los actos discrecionales no estuvieran suficientemente motivados, estaríamos en el reino de la arbitrariedad. Como ya se dijo, este concepto está prohibido por nuestra Constitución, pues en el Estado de Derecho se sustituye, con carácter general, la subjetividad en el ejercicio del poder por la objetividad, así como la irracionalidad por la racionalidad.

En sentido amplio, la sentencia del Tribunal Supremo del 1 de junio de 1999 es bien clara cuando sostiene que:

La discrecionalidad, en cualquiera de sus variantes, parte de la posibilidad de elegir entre un mayor o menor abanico de opciones o, si se prefiere, resulta que su ejercicio permite una pluralidad de soluciones justas, o de optar entre alternativas que, en general, sean igualmente justas desde el punto de vista del Derecho o, tal vez mejor, razonables, desde el mismo punto de vista, por lo que el ejercicio de la potestad discrecional presupone una opción entre varias posibles, y una razonabilidad en un marco socio-cultural determinado, pero precisamente por ello, la decisión discrecional exige, como inseparable de ella, la motivación, que es lo que garantiza que se ha actuado racionalmente y no arbitrariamente, y la que permite un adecuado control de los actos discrecionales, exigiéndose así una motivación suficiente, que al menos exprese apoyo en razones que permitan conocer cuales han sido los criterios esenciales fundamentales de la decisión (STC 14/1991), fórmula un tanto vaga si se quiere, pero que tiene la ventaja de poder medirse caso por caso si se cumple o no con la suficiencia.

La discrecionalidad del acto nunca es absoluta o total, pues siempre habrá algún elemento del acto de naturaleza reglada, procedimental o formal. En estos casos, la motivación habrá de circunscribirse a esa zona de discrecionalidad, de manera que la luz se proyecte sobre las razones internas en cuya virtud la administración ha operado dentro del área de libre disposición del que disfruta en algunos casos con el fin de servir objetivamente el interés general. Como ha señalado también el Tribunal Supremo en su sentencia del 3 de febrero de 1998, cuando procede en el marco de la discrecionalidad, la administración pública «ha de apreciar y considerar, con adecuada ponderación y supuesto por supuesto, los intereses públicos y privados puestos en juego y los demás elementos de juicio requeridos por la norma, reflejando consecuentemente en la resolución, mediante una motivación suficiente y congruente [...] las causas que determinen circunstancialmente, la concesión o no (sobre todo en caso de denegación) de la licencia o autorización». He aquí

DISCRECIONALIDADY MOTIVACIÓN DEL ACTO ADMI-

NISTRATIVO EN LA LEY ESPAÑOLA DE PROCEDIMIENTO ADMINISTRATIVO

DISCRETIONALITY AND MOTIVATION OF ADMINISTRATIVE ACT ON ADMINISTRATIVE PROCEDURE IN SPANISH LAW 
algunos elementos que son relevantes para comprender mejor el alcance de la motivación.

En efecto, debe hacerse caso por caso. No hay fórmulas de estilo para motivar los actos porque, salvo que estemos en presencia de los actos en masa, cada acto es individual, y ha dictado con arreglo a unas determinadas circunstancias. Además, es menester que la operación jurídica de motivación se haga con ponderación y de forma congruente con las exigencias normativas y de interés general que siempre han de estar presentes en todas las cuestiones que se refieren al acto administrativo en general.

La motivación, según el artículo 54 de la LRJAPPAC y la jurisprudencia, ha de ser — como ya hemos indicado- suficiente y congruente. Suficiente para que los particulares puedan conocer fácilmente las razones en las que se apoyó la administración para resolver, y congruente con el interés general que la administración ha de servir siempre de manera objetiva. Además, la jurisprudencia reclama de la operación de motivación un ejercicio jurídico de ponderación de intereses y, por supuesto, un contraste adecuado con el caso concreto del que se trate. Es decir, cuando nos encontramos ante motivaciones genéricas, abstractas, que no hacen referencia alguna $\longrightarrow$ o insuficiente- al caso concreto, nos encontramos ante motivaciones que no dan los mínimos exigibles. A veces, la administración recurre a fórmulas de estilo previamente elaboradas, que se pretende sean motivaciones de actos administrativos. Sin embargo, salvo que se trate de casos idénticos, lo lógico es que cada caso se trate individualmente, y que, también individualmente, se proceda a la motivación correspondiente.

En séptimo lugar, el legislador dispone que habrá de motivarse los actos que deban serlo, en virtud de las correspondientes disposiciones legales o reglamentarias. En el párrafo segundo del artículo 54, encontramos una referencia expresa a la motivación en los tipos de actos que resultan de procedimientos selectivos y de concurrencia competitiva, en cuyo caso «han de quedar acreditados en el procedimiento los fundamentos de la resolución que se adopte». En estos supuestos, es evidente que el alcance y la extensión de la motivación será diferente de los casos normales u ordinarios. Por ejemplo, en un tribunal de selección de personal al servicio de la administración pública, la motivación se realiza en virtud de los criterios previamente establecidos y proyectados sobre los ejercicios de cada opositor. Así, la motivación resultará de las notas o los comentarios de los miembros del tribunal que se recogerán en las actas de las sesiones, y también de las anotaciones que realizan los citados miembros del tribunal de selección en relación con las diferentes intervenciones de los candidatos. Si no se acreditaran las razones de las decisiones del tribunal, aunque hayan sido expresadas oralmente en las 
deliberaciones ante los terceros o interesados en el procedimiento, se estaría procediendo en un marco de oscuridad, misterio o enigma que choca frontalmente con los postulados del Estado de Derecho, que es lo que, precisamente, la motivación de los actos administrativos pretende combatir.

\section{REFLEXIÓN FINAL}

El Tribunal Supremo español ha entendido, por sentencia del 29 de mayo de 2001, que «la Administración ha de expresar las razones que le inducen a otorgar preferencia a uno de los solicitantes frente al resto de los concursantes, haciendo desaparecer así cualquier atisbo de arbitrariedad y permitiendo, al mismo tiempo, que el no beneficiario pueda contradecir, en su caso, las razones motivadoras del acto y el órgano judicial apreciar si ha actuado o no dentro de los límites impuestos a la actividad de los poderes públicos». Además, «la exigencia de motivación no puede ser suplida por la simple fijación de puntuaciones [...], con tal exigencia no se trata de sustituir el criterio técnico de la Administración, sino de conocer en qué ha consistido este y cuáles han sido los datos determinantes de la decisión». En el supuesto de que la fundamentación de la decisión se hace en función de puntuaciones o calificaciones, tales puntuaciones o calificaciones han de realizarse a partir de los criterios previamente determinados, los cuales son aplicados sobre cada uno de los concursantes sin que sea suficiente la mera exposición de las notas correspondientes sin soporte motivador. Más bien, es menester que tales calificaciones o puntuaciones estén fundadas sobre determinadas anotaciones o glosas de los miembros del tribunal de selección, las cuales normalmente constarán en las actas de las reuniones deliberativas, y estarán contenidas en el expediente del correspondiente concurso u oposición. 